\title{
Educação, trabalho e o delineamento de novos perfis profissionais: o bibliotecário em questão ${ }^{1}$
}

\section{M aria da Conceição C almon A rruda}

M estre em ciência da informação, bibliotecária da Procuradoria-Geral da Câmara M unicipal,

E-mail: marruda@cmrj.gov.br.

\section{Regina Maria M arteleto}

Professora do Programa de Pós-Graduação em Ciência da Informação, Convênio CNPq/IBICT - UFRJ/ECO.

E-mail: remartel@ prolink.com.br

\section{Donaldo Bello de Souza}

Professor da Faculdade de Educação da U niversidade do Estado do Rio de Janeiro - UERJ.

\section{Resumo}

O movimento de reestruturação da qualificação profissional não é exclusivo da área de informação, mas se insere nas transformações por que passa o mundo do trabalho. O texto contextualiza o cenário em que emerge a demanda por um trabalhador mais qualificado e mostra a discussão em torno das qualificações necessárias para que o bibliotecário interaja como sujeito frente aos novos requerimentos do mundo do trabalho.

Palavras-chave

Bibliotecário; Qualificação profissional; Trabalho-Educação.

Education, work and job skills: the librarian on focus

\begin{abstract}
The demand for new skills and qualifications is not exclusive information professionals. Thus the general context in which this happens is analysed and the new skills librarians are expected to develop are discussed.
\end{abstract}

\section{Keywords}

Librarian; Job skills; Education; Trainning.

\section{IN T RO DU ÇÃ O}

0 atual estágio de desenvolvimento tecnológico, rico em possibilidades de armazenamento, acesso e disseminação de informações, traz novamente à pauta de discussão 0 papel do profissional da informação em relação ao aparato científico-tecnológico e sua afirmação como gestor da informação. Contudo, sob uma nova materialidade: a informação, no novo modelo econômico, é percebida como um valor, dada a possibilidade de vir a se transformar em conhecimento e em inovação tecnológica. Esta nova dimensão da informação, aliada ao desenvolvimento tecnológico, desvincula a informação de espaços restritos e de monopólios profissionais.

N este novo cenário, a tecnologia possibilita autonomia ao usuário, demandando nova postura dos profissionais da informação, que passam a ter seu campo de atuação ampliado e redimensionado. Conjugado ainda aos novos modelos organizacionais e de gestão do trabalho, que privilegiam, entre outros fatores, as descrições de cargos genéricas e a flexibilidade funcional, faz com que a área de informação passe a congregar profissionais de outros campos de atuação, causando tensão e insegurança aos profissionais tradicionalmente vinculados a ela.

O s espaços antes restritos em que estes profissionais atuavam perdem o monopólio sobre o gerenciamento da informação, o qual passa a ser efetuado de forma descentralizada e por profissionais oriundos de outrasáreas do conhecimento. 0 acesso remoto possibilita a conexão com fontes de informação geograficamente distantes e a autonomia dos usuários, que passam a contar com formas alternativas de acesso.

A s mudanças em pauta suscitaram uma série de questões na área de informação tanto no que diz respeito ao "novo" perfil do profissional da informação, quanto à capacidade do setor acadêmico em fornecer uma resposta adequada ao mercado de trabalho na forma de cursos de formação profissional e de educação continuada.

\footnotetext{
${ }^{1}$ Este artigo tem como base a dissertação de mestrado defendida, em agosto de 1999, no Programa de Pós-Graduação em Ciência da Informação, Convênio CN Pq/IBICT - UFRJ/EC O, sob a orientação da professora Regina Maria $M$ arteleto e a co-orientação do professor Donaldo Bello de Souza.
} 
0 objetivo deste artigo é mostrar que a demanda por um novo perfil profissional não é exclusiva da área de informação, mas se insere e se articula com as mudanças introduzidasno mundo do trabal ho e na demanda do setor produtivo por um trabalhador mais qualificado. Para dar conta deste objetivo, estabelecemos a conexão com a área de Trabalho-Educação ${ }^{2}$ a fim de identificar e compreender os elementos e as materialidades que estão afetando 0 mundo do trabalho e contribuindo para a conformação de um novo modelo de qualificação profissional.

Este artigo divide-se em seis partes: após a presente, de caráter introdutório, analisamos as mudanças no mundo do trabalho; na terceira estudamosa emergência de novos perfis profissionais; a quarta parte trata dos efeitos das mudanças no padrão de qualificação profissional na área de informação; a quinta mostra a discussão em torno das qualificações necessárias para que o bibliotecário interaja como sujeito diante dos novos requerimentos do mundo do trabalho; por fim, na conclusão, indicamos que as mudançasno perfil profissional não são exclusivas da área da informação, mas se articulam, como as demais profissões, com as transformações em curso no mundo do trabalho.

\section{MUDANÇAS NO MUNDO DO TRABALHO}

A regulamentação do trabalho assalariado, que teve início no século passado e alcançou seu apogeu no Estado Providência, está sendo desmontada sem que o modelo de compromisso social entre capital e trabalho tenha alcançado a totalidade dos países e o conjunto dos trabalhadores. 0 redimensionamento da relação capital/ trabal ho e a revisão dos direitos trabal histas passam a ser parte integrante da estratégia adotada pelos países para superação da crise econômica e implementação do novo modelo econômico, produzindo modificações na organização do trabalho e a aparente subtração do trabalho, principalmente do trabalho assalariado, como forma de integração social, de mobilidade ascendentee de garantia de um futuro melhor para o indivíduo e sua família (Castel, 1998).

\footnotetext{
${ }^{2} \mathrm{~A}$ área de trabalho-educação é parte do campo da educação e teve sua consolidação formal, no Brasil, em 1981, quando o professor M iguel A rroyo criou, na reunião anual da A ssociação $\mathrm{N}$ acional de PósGraduação em Educação (A N PEd), o grupo Educação eTrabalho. A criação deste grupo foi motivada pela necessidade de proporcionar maior visibilidade à área de trabalho-educação, que estava relegada a segundo plano nos Programas de Pós-Graduação em Educação. U m dos objetivos da área de trabalho-educação é o estudo da relação entre a educação e o processo produtivo no contexto político-econômico e social em que esta se inscreve (Kuenzer, 1988).
}

Segundo Castel (1998), estaríamos diante não do desaparecimento do trabalho, mas de um movimento de crescente precarização do mesmo, manifesto pela diminuição da oferta do pleno emprego, pelo aumento de contratos de trabalho por tempo determinado, pela desabilitação de uma parcela da população para o emprego e pela crescente dificuldade de absorção dos jovens pelo mundo do trabalho. $E$, independentemente das materialidades dos países, em menor ou maior grau, identifica-se um movimento de uniformização na adoção de políticas trabalhistas desvinculadas das conquistas dos trabalhadores e do Estado Providência.

Em sua crítica à tese da não-centralidade do trabalho na sociedade contemporânea (O ffe, 1989a; O ffe, 1989b; Habermas, 1987), Castel (1998) utiliza-se de dados que demonstram que o número de indivíduos vinculados a uma atividade formal não decresceu na França. Segundo o autor, o que se observa é o incremento do emprego precário e a intensificação do trabalho, este último caracterizado pelo aumento de tarefas, horas trabalhadas e pela imbricação do trabalho no tempo livre dos indivíduos.

“Inúmeras formas modernas de emprego pedem (...) uma disponibilidade constante e, a rigor, uma conversão total aos valores da empresa. 0 medo da dispensa acentua ainda mais essa pressão; o indivíduo é levado a pensar no trabalho fora da situação de trabalho e tenta garantir-se contra uma má avaliação superinvestindo no trabalho" (Castel, 1998 , p. 156).

0 emprego de meio período frutificou e deu origem a novos arranjos trabalhistas, como, por exemplo, o emprego de fim de semana, de meia semana, zero hora etc., dotando as organizações com um contigente de trabal hadores móvel e flexível. É importante ressaltar que não se identifica um consenso entre os autores sobre os efeitos da flexibilização para o trabalhador.

Toffler (1980) percebe o emprego parcial como mutuamente benéfico para trabalhadorese empregadores, liberando os primeiros para o desenvolvimento de tarefas e atividades particulares e possibilitando aos empregadores as condições ideais para adequação da força de trabal ho de acordo com as oscilações da economia globalizada e do mercado interno.

O utros autores, Freeman (1995) e H arvey (1996), por exemplo, também identificam um diálogo entre trabalhadores e empregadores nos arranjos de trabalho parcial, masalertam sobrea crescente terceirização da força de trabalho, sua exclusão dos benefícios oferecidos aos empregados centrais e sua descartabilidade. 
Castells (1996) chama a atenção para o risco de que, sem regulamentação, evolua para um patamar em que a flexibilização seja a regra, e não a exceção nas condições de trabalho, pois, apesar da mobilidade do capital e dos apelos da globalização, os dados analisados pelo autor sobre a mobilidade da força de trabalho indicam que 0 mercado de trabal ho só se globaliza para um pequeno grupo da população mundial, altamente qualificado.

A lém disso, ao valorizar o trabalho qualificado, o novo modelo econômico expõe a fragilidade do trabalho não qualificado, cujo custo se torna muito alto para sua manutenção nas organizações, gerando uma demanda decrescente, pois:

"Q uando governos e organizações não podem efetuar mudanças nos contratos de trabalho, como na U nião Européia, o custo do trabalho não qualificado torna-se muito al to com referência às commodities comercializadas com os países de industrialização recente. Segue-se o desemprego da força de trabal ho não qualificada que era, comparativamente, muito dispendiosa, tendo em vista sua baixa qualificação" (C astells, 1996, p. 237-238).

Esse cenário é agravado pelo fato de a flexibilização da produção e as tecnologias de informação permitirem às organizações, além da redução de custo, a contratação de mão-de-obra qualificada em qualquer parte do planeta. A s organizações podem utilizar - sem necessidade de deslocamento físico, nem perda de qualidade - os serviços de trabalhadores altamente especializados, locados em qualquer região do globo que possua uma infra-estrutura de informação e comunicação adequada e um ambiente político-econômico receptivo. Fazem parte dessa nova força de trabalho:

“(...) engenheiros e cientistas de computação [indianos] que recebem aproximadamente $20 \%$ do salário pago nos Estados U nidos para atividades similares. 0 mesmo ocorre no setor financeiro e no de negócios em Singapura, $\mathrm{H}$ ong Kong e T aipei" (C astells, op. cit., p. 238).

Paralelamente a esse quadro de exclusão, centralização, desemprego, desabilitação e fragmentação presente no mundo do trabalho, ressurgem os modelos de valorização do ser humano que exaltam a importância de oferecer ao trabalhador saúde, educação, reconhecimento de seu desempenho (ascensão profissional, gratificação, prêmios), percebendo-o como um colaborador da organização. De acordo com Frigotto (1996) e Kuenzer (1995), esse cenário paradoxal só pode ser entendido a partir da compreensão de que essa valorização está ligada à própria fragilidade do modelo flexível, de sua dependência do envolvimento humano.

"Se por um lado retomam-se os investimentos no 'homem', de modo a viabilizar a extração de mais-valia extraordinária através de novas estratégias, por outro lado, o princípio continua a ser a velha concepção taylorista de redução de tempos mortos (...) buscando novas formas de realização do taylorismo 'casado' com a teoria das relações humanas que gerou o comportamentalismo na década de 50 e que apenas se sofistica, a partir das determinações da modernidade, que contraditoriamente expressam, ao nível dasidéias, um aparente maior respeito pelo homem, sua razão, seus sentimentos e seus direitos, a par da realização material de crescentes formas de exclusão do emprego, do consumo, da educação, da saúde, etc." (Kuenzer, 1995, p. 4).

A inda de acordo com K uenzer, a organização flexível, para se concretizar, precisa contar com um núcleo central motivado, envolvido e disposto a internalizar os objetivos e as metas da organização. 0 capital humano passa a ser 0 fator diferencial de ganho, uma vez que o máximo de produtividade calcado em máquinas tem um. A s organizações passam a preferir modelos e ferramentas organizacionais que privilegiem a integração funcional e organizacional, assim como trabal hadores aptosa articular seu conhecimento em função do novo padrão produtivo.

0 enfraquecimento dos sindicatos, aliado à retração do mercado de trabalho, permite às organizações maior autonomia no estabelecimento de um perfil profissional adequado aos seus interesses. 0 trabalhador, além de conviver com a precarização do emprego, com novos arranjos de trabalho, com o desemprego, tem de responder à exigência de maior qualificação. A mpliam-se os requisitos profissionais. Em adição àsqualificações formais, são exigidas capacitações tácitas ${ }^{3}$ que permitam ao trabalhador atuar como agente integrador na dinâmica pesquisa-produção-vendas, o que leva a um novo perfil profissional que privilegia a criatividade, a interatividade, a flexibilidade e 0 aprendizado contínuo.

\footnotetext{
${ }^{3}$ Jones \& W ood (1984) definem o conhecimento tácito como 0 conhecimento anterior, fruto da experiência e da intuição do trabalhador.
} 


\section{Educação, trabalho e o delineamento de novos perfis profissionais: o bibliotecário em questão}

\section{A EMERGÊNCIA DE NOVOS PERFIS PROFISSIONAIS}

Conforme postulado anteriormente, o novo modelo econômico interpõe um novo perfil profissional que requer, além de maior qualificação profissional, maior envolvimento emocional e social do trabalhador. Elegese como ideal o profissional que potencialize a comunicação, a interpretação de dados, a flexibilização, a integração funcional e a geração, absorção e troca de conhecimento. Este, portanto, deve ser capaz de operacionalizar seu conhecimento profissional de modo integrado às suas aptidões e vivências socioculturais. 0 trabalhador adestrado, característico do modelo fordista ${ }^{4}$, deixa de atender aos requisitos do novo padrão produtivo. É necessário um profissional capaz de interpretar dados e sinais emitidos pelos novos sistemas autômatos, agindo pró-ativamente a partir desses dados, atuando como agente do processo de inovação. Em vez de ser responsável por uma só tarefa, o que caracterizava a especialização, solicita-se que ele cumpra diversas tarefas, que seja polivalente ou multifuncional, demonstrando responsabilidade pelo seu processo de trabalho ${ }^{5}$.

A opção por equipes de trabalho é uma estratégia utilizada pelas organizações para obtenção da polivalência. A s equipes viabilizam a integração de profissionais de áreas diversas, com um nível de qualificação mais elevado, direcionados à resolução de problemas. Essas equipes podem ser inter, multi ou transdiciplinares, dependendo da estratégia organizacional. No trabalho em equipe, a hierarquia é regulada por seu mediador e pelos diversos papéis que seus integrantes assumem no decorrer dos projetos. Seu ritmo de trabalho e o desempenho de seus integrantes são subordinados aos prazos e metas fixados pela organização. 0 sindivíduos interagem em grupos, mas não são parceiros do grupo, e sim da organização, comprometidos com sua visão estratégica e sua missão organizacional (M achado, 1996). É dentro dessa dinâmica que as equipes se auto-avaliam, avaliam seus integrantes e são avaliadas pela organização.

\footnotetext{
${ }^{4} 0$ fordismo é entendido aqui como o processo de produção em massa voltado para um consumo de massa, aliado a uma racionalização de trabal ho taylorista, que não pode ser generalizado como padrão universal, mas que norteou a produção capitalista no século 20.

${ }^{5}$ É importante diferenciar o trabalhador polivalente do trabalhador multifuncional. Enquanto o primeiro é submetido a maior número de rotinas/tarefas em adição às que realiza, sem que com isso ocorra maior intelectualização do trabalho, o segundo é exposto a situações complexas, que requerem maior atuação cognitiva (Salermo, 1996).
}

Segundo M achado (1996), no trabal ho em equipe a semiautonomia é regulada por um tempo informático e pelos laços de responsabilidade e motivação dos trabalhadores com a empresa. 0 êxito e absorção de conhecimento de uma equipe pode não se transmutar em conhecimento para outras equipes ou mesmo para todos os indivíduos que as compõem. Já D eluiz (1994) vê o trabalho em equipe como uma oportunidade para a emancipação do trabalhador, tanto no que diz respeito à organização dos trabalhadores e reivindicação por melhores condições de trabalho, quanto à participação no processo decisório da organização. N esse sentido, a valorização da comunicação no novo modelo é um fator que pode atuar como elemento integrador.

Contudo, a demanda por um profissional mais integrado e responsável não necessariamente se apresenta como contrapartida para a ampliação de sua participação no processo decisório das organizações (Bourdieu, 1998; Kuenzer, 1995; Lojkine, 1995), nem uma superação do taylorismo, o que ocorre é que o controle sobre o trabalho deixa de ser exercido de fora para dentro, na forma taylorista pura, para ser internalizado pelo trabalhador através de seu comprometimento com osvalores, a missão e os objetivos da organização. A análise de Bourdieu (1998, p. 225) é que, longe de oferecer uma transição para uma forma de organização do trabalho que torne possível o enriquecimento da tarefa, os novos modelos de gestão estabelecem, a partir de estudos científicos e acadêmicos, ferramentas organizacionaisque permitem "tirar proveito de maneira metódica esistemática ${ }^{6}$ de todasas possibilidades que a ambigüidade do trabalho oferece objetivamente às estratégias patronais". Muda-se a roupagem, mas a essência de controle e dominação permanece subjacente sob a forma de desemprego, de precarização do emprego e das condições de trabalho.

A pesar de desenvolver uma análise similar, Lojkine (1995) identifica, na própria característica do novo modelo, que requer dos trabalhadores integração e interatividade com os processos desenvolvidos pela organização, uma oportunidade para a superação da divisão histórica entre aqueles que planejam e aqueles que executam o trabal ho.

\footnotetext{
${ }^{6}$ Grifo do autor.
} 
A s alterações no perfil profissional não se restringem ao âmbito da qual ificação profissional e da gestão do trabalho, mas abrangem o conteúdo e a forma como o trabalho é realizado, como o trabalhador se relaciona e se socializa no ambiente de trabalho. A tingem a subjetividade do sujeito, invadindo seu espaço social, seu comportamento individual e coletivo. N ecessita-se de um profissional flexível, apto a atuar em situações de trabalho diferenciadas e a mobilizar seu conhecimento em prol da organização.

$\mathrm{N}$ o entanto, do ponto de vista dos enfoques que versam sobre o trabalho no processo de produção capitalista, não há consenso. Segundo Paiva (1989), coexistem quatro teses básicas:

(1) Tese da Desqualificação Progressiva da Força de T rabal ho: como ocorreu na passagem da fase artesanal para a manufatura, no capital ismo ocorre, tendencialmente, a desqualificação do trabalhador;

(2) Tese da Requalificação: a nova base técnica possibilitaria uma elevação da qualificação média dos trabalhadores;

(3) T ese da Polarização das Q ualificações: criação efetiva de poucos postos de trabalho de qualidade que exigiram profissionaisaltamente qual ificados em oposição à geração de muitas vagas para profissionais pouco qualificados, com aprofundamento das diferenças salariais entre trabalhadores qualificados e trabalhadores não qualificados;

(4) T ese da Q ualificação A bsoluta e da Desqualificação Relativa: elevação da qualificação média e redução da qualificação relativa "o nível de conhecimentos atingidos pela humanidade se reduziria se comparado com épocas pretéritas" (Paiva, 1989, p. 4-5).

Jones \& W ood (1984), em sua argumentação contra a tese da desqualificação e substituição de mão-de-obra, destacam a importância da relação custo versus benefício para as organizações na adoção de novas tecnologias. Salientam que a opção por uma tecnologia não estaria unicamente vinculada ao controle sobre os trabal hadores, mas também a uma série de fatores que englobam a estratégia da organização, o mercado consumidor, a concorrência, o mercado de trabalho etc., os quais seguramente são levados em consideração quando da opção ou não por uma tecnologia.
No que tange à tese da polarização das qualificações, hegemônica nos anos 70, H irata (1996) sustenta que esta não teve comprovação empírica nas pesquisas realizadas na década seguinte, em virtude de ter ocorrido uma requalificação em larga escala dos trabalhadores, decorrente da adoção pelas empresas de um novo padrão produtivo e de organização do trabalho. C arvalho (1996), M achado (1991) e Paiva (1989) também sinalizam para um aumento médio na qualificação dos trabalhadores oriundo da adoção dosnovos modelos de gestão e dasnovas tecnologias, mas ressaltam que esse aumento é heterogêneo, não podendo ser generalizado para o conjunto da população.

No que diz respeito à desabilitação profissional ${ }^{7}$ e ao surgimento de novas ocupações, a anál ise de A ssis (1996) afirma que, com a automação, existe uma tendência de al gumas ocupações virem a ter sua posição redefinida e/ou desaparecerem e de criação de outras. Todavia, a autora destaca que não se identifica uma ruptura entre as ocupações dimensionadas sobre a nova base técnica e as ocupações preexistentes, havendo, portanto, uma qualificação adicional, a qual pode ser construída a partir de um conhecimento já sedimentado, passando a se constituir no ponto de partida da nova qualificação. A consideração da existência de uma nova ocupação implicaria que a incorporação de inovações tecnológicas na rotina do trabalho gerou mudanças tão intensas no conteúdo deste que as qual ificaçõesanterioressetornaram ultrapassadas: "nessa situação, não se trata de adaptar ou reconverter conhecimentos e habilidades do sistema convencional para o 'novo', pois as funções emergentes prescindem destes” (A ssis, 1996, p.191).

Sem subtrair a importância da demanda por maior qualificação do trabalhador no design do novo perfil profissional, é importante destacar a valorização de qualificações tácitas na composição deste perfil e o forte apelo para o comprometimento efetivo dos trabalhadores com a organização. Essa transição é identificada pela área de trabalho-educação como uma oportunidade e, ao mesmo tempo, como uma ameaça: uma oportunidade para se construir um modelo de educação integral, que capacite osindivíduos como agentes de seu destino e de sua história (Frigotto, 1996; M achado, 1992) e, em concomitância, uma ameaça de desvalorização do padrão escolar e de estabelecimento de modelos de reconhecimento e certificação pelo setor produtivo que não habilitem os indivíduos com saberes concretos e duradouros ( Lope \& M artin A rtiles, 1998; Stroobants, 1997; T anguy, 1997).

${ }^{7} \mathrm{~A}$ desabilitação profissional ocorre quando a qualificação profissional do indivíduo já não se enquadra ao espaço produtivo. 


\section{Educação, trabalho e o delineamento de novos perfis profissionais: o bibliotecário em questão}

\section{OS EFEITOS DAS MUDANÇAS NA ÁREA DE IN FORMAÇÃO}

Os profissionais da informação estão sendo instados a reafirmar sua importância e seu valor para o mundo do trabalho, em meio à transição para um novo modelo de qualificação profissional. U ma controvérsia que vem permeando a área de informação é a retirada de qualquer referência à palavra biblioteca do nome das instituições de formação profissional, que passariam a ser nomeadas pela expressão informação ou por ciência da informação. 0 argumento que respalda essa mudança é que a palavra biblioteca restringe 0 âmbito de atuação dos profissionais e dificulta a identificação dos mesmos pelo mercado de trabalho, para atuação em outros espaços profissionais. A tese contrária a essa alteração destaca que 0 estudo da informação como fenômeno não fornece o suporte teórico necessário para a complexidade que envolve o conceito de biblioteca (C rowley \& Brace, 1999).

Schiller (1996) atribui as transformações por que estão passando as bibliotecase os bibliotecários americanosnão só à forma mercadoria que a informação está assumindo nesse fim de século, uma vez que desde a invenção da imprensa ocorre o comércio e o empacotamento do conhecimento, mas ao estabelecimento de uma política de eficiência e lucratividade nos serviços públicos, que não condiz com a tradição de gratuidade e livre acesso defendida pelos bibliotecários. Para 0 autor, em um momento em que as bibliotecas se orientam para clientes, para a geração de recursos, é necessário um profissional com a mesma visão, e não aquele voltado para problemas humanísticos, como, por exemplo, o acesso e disponibilização democrática de informação.

Com o objetivo de identificar de que forma os profissionais da informação estão lidando com as mudanças no mundo do trabalho e em seu perfil profissional, a Federação Internacional de Informação e D ocumentação (FID) criou, em 1991, o Grupo de Interesse Específico sobre Papéis, Carreiras e Desenvolvimento do Moderno Profissional da Informação (SIG FID/M IP), que realizou uma pesquisa mundial entre os profissionais da área para identificar seu perfil "moderno"8.

\footnotetext{
${ }^{8} 0$ resultado desse levantamento já está disponível no website da FID, e a proposta é atualizá-lo a cada dois anos.
}

No item da pesquisa da FID relativo às mudanças que estão ocorrendo no conteúdo do trabalho nos últimos cinco anos, a tecnologia desponta como propulsora das principais modificações, seguida por elementos de gestão organizacional e do trabal ho, tais como intensificação do trabalho, aumento da responsabilidade individual ${ }^{9}$, influência do mercado internacional e da competitividade e outros. $\mathrm{N}$ o que diz respeito às qualificações necessárias para ascensão profissional, as respostas mais freqüentes foram as seguintes: domínio das tecnologias de informação, aquisição de mais de um idioma, capacidade de comunicação e de relacionamento interpessoal, gerenciamento etc. U ma das conclusões da pesquisa que merece destaque é que não se identifica uma unicidade nas qualificações requeridas ao "moderno" profissional da informação $0^{10}$. Q uanto às principais barreiras do desenvolvimento profissional, detectam-se dois padrões de respostas, um relacionado a qualificações e habilidades a serem desenvolvidas, tais como treinamento, qualificação, atitudes comportamentais, e outro referente a fatores circunstanciais, como gênero, idade, cultura organizacional etc.

$\mathrm{N}$ a visão da vice-presidente da FID , M argarita $\mathrm{A}$ Imada de A scencio:

"N enhum profissional da atualidade tem condições de reunir todas as habilidades, conhecimentos e competências necessários para interagir e equacionar os problemas decorrentes dos fluxos de informação e conhecimento. Para resolvê-los é necessária a formação de equipes interdisciplinares em todos os níveis e processos: estratégicos, gerenciais e operatórios (A Imada de A scencio, 1997, p. 9)"11.

\footnotetext{
${ }^{9}$ Responsabilidade individual significa, no novo modelo econômico, 0 comprometimento do indivíduo com seu processo de trabalho e com a missão corporativa da organização.

${ }^{10} \mathrm{Ver}$ item Trends and Issues da pesquisa. H ttp//fid.conicyt.cl:8000/ mip12.htm. A rquivo consultado em 15/06/1999.

${ }^{11}$ "Ningún profesional en la actualidad puede tener todas las habilidades, conocimientos y competencias necesarias para ir resolviendo los complejos y multifacéticos problemas del mundo actual de flujos de información y conocimiento. Para resolverlos hace falta incorporar grupos interdisciplinarios en todos los niveles e los procesos: estratégicos, gerencialies y operativos" (A Imada de A scencio, 1997, p. 9).
} 
A etapa brasileira da pesquisa foi realizada de acordo com as recomendações da FID, sob o patrocínio do Instituto Euvaldo Lodi do D istrito Federal (IEL/DF), em parceria com o Instituto Brasileiro de Informação em Ciência e T ecnologia (IBICT). O s responsáveis por unidades de informação especializadas em ciência e tecnologia integrantes do sistema Comut ${ }^{12}$ compõem o universo pesquisado, devido à inexistência de um cadastro nacional por categoria profissional. 0 levantamento foi realizado mediante 0 envio de questionários e posterior tabulação dos dados ${ }^{13}$. Um de seus desdobramentos é fornecer subsídios ao IEL/D F e ao IBICT para formulação de cursos de treinamento e educação continuada para os profissionais da informação (T arapanoff, 1997). Entre as variáveis pesquisadas, concentramo-nos na análise do perfil do profissional informante eno perfil dasmudanças e tendências.

A pesquisa constata que o perfil do profissional informante é composto prioritariamente de bibliotecários, sendo os demais profissionais oriundos de áreas diversas, e que 0 grupo pesquisado apresenta um percentual significativo de pós-graduadoslato sensu (39,50\%) e stricto sensu (12\%). Em relação à Educação Continuada, esta ocorre principalmente no ambiente de trabalho, voltada para a assimilação de ferramentas gerenciais, o que não constitui uma surpresa, visto que a pesquisa foi direcionada aos responsáveis pelas unidades de informação. $A$ educação a distância só foi vivenciada por $10 \%$ dos pesquisados.

Na categoria M udanças e Tendências, a tecnologia é indicada como o principal fator de mudanças nosúltimos três anos. No que tange ao conhecimento técnico e habilidadesnecessárias para a virada do milênio, destacamse o desenvolvimento de produtose serviços, a cooperação em redes e as novas tecnologias. Q uanto às qualificações necessáriaspara o desenvolvimento profissional, desponta em primeiro lugar o treinamento para a inovação e desenvolvimento de produtos e processos - seguido pelo treinamento para cooperação em redes, novas tecnologias, treinamento para a qualidade; treinamento em recursose disponibilidade informacionais, treinamento para a competitividade, ordenamento/cadastramento da informação eletrônica por meio da criação de cadastros em W orld W ide W eb e outros.

\footnotetext{
12 Sistema de solicitação de fotocópias de documentos ou parte de documentos entre unidades de informação.

${ }^{13}$ D os 881 questionários enviados, 401 foram devolvidos (Tarapanoff, 1997).
}

A s mais citadas entre as barreiras para o desenvolvimento profissional foram as seguintes: inadequação da grade curricular dos cursos de biblioteconomia, documentação e ciência da informação à realidade do mercado de trabalho; a carência de apoio da instituição para a educação continuada e o treinamento em serviço; falta de motivação dos profissionais para a educação continuada; por fim, a oferta reduzida de cursos voltados para in ovações tecnológicas.

Embora a pesquisa brasileira tenha se restringido aos profissionais vinculados à área de ciência e tecnologia, o diagnóstico sobre a necessidade de educação continuada e de maior envolvimento com os objetivos da organização é concorrente com o que emerge da literatura analisada sobre mudança no perfil dos profissionais da informação.

$\checkmark$ ale destacar que a automação total ainda não faz parte da realidade das unidades de informação pesquisadas e que a multiplicidade de recursos informacionais dificulta uma tipologia das diversas áreas de atuação dos profissionais da informação. Estes fatos sinalizam para um desafio referente à capacidade dos cursos de formação profissional em desenvolver/ajustar seus currículose cursos de educação continuada às mutações da sociedade de forma a abranger todas as nuanças da área de informação e responder às necessidades dos profissionais.

\section{A VISÃO DOS CURSOS DE FORMAÇÃO PROFISSIONAL}

A discussão em torno das qualificações necessárias para que o profissional da informação interaja como sujeito diante das demandas do mundo do trabalho não érecente, muito menos a pressão para que os cursos de formação profissional adaptem seus currículos às transformações da sociedade.

Segundo M enou (1996, p.7), muitas das atividades eleitas como novas estão sendo discutidas desde a década de 50. A ssim, estar-se-iam confundindo os novos modelos organizacionais e a sofisticação do aparato técnico com a emergência de um novo profissional, embora "a conceituação, o quadro operacional, as necessidades" se mantenham.

O s textos da década de 80 (Figueiredo \& Lima, 1986; Robredo, 1986) orientam os profissionais para 0 aprofundamento de estudos nas áreas de administração, gerenciamento de bases de dados e de recursos humanos, marketing de serviços, tecnologia de informação, a fim de que os mesmos possam responder às demandas de qualificação do mercado de trabalho. 


\section{Educação, trabalho e o delineamento de novos perfis profissionais: o bibliotecário em questão}

Figueiredo \& Lima (1986) destacam que o novo cenário científico-tecnológico, aliado a uma nova conformação político-econômica, leva à valorização da informação como insumo do processo econômico, redefinindo as qualificações do profissional da informação para o mundo do trabalho: passa-se a requerer capacidade gerencial e administrativa voltada para os acervos informacionais, assim como educação continuada. N esta mesma linha, Robredo (1986) afirma que o desenvolvimento tecnológico, aliado ao novo modelo econômico, que passa a valorizar a informação em sua estrutura de troca, tem como uma de suas conseqüências a redefinição do conceito de biblioteca e do perfil do profissional da informação. Identifica, ainda, a necessidade de adaptação do currículo, em vista da incorporação de novasatividades ao conteúdo do trabalho dos bibliotecários:

“I) a aplicação dos recursos de processamento eletrônico de dadose de telecomunicações; II) astécnicasgerenciais; III) o desenvolvimento dos esquemas cooperativos com vistas à organização de redes; IV ) o desenvolvimento de técnicas de análise da informação e indexação" (R obredo, 1986, p. 61).

Podemos depreender, a partir do enfoque dos autores acima referendados, a existência de consenso em torno da ocorrência de uma intensificação do trabalho do profissional da informação, que tem novas atividades acrescidas ao seu processo detrabalho, as quais demandam maior envolvimento intelectual.

Em paralelo a essa intensificação do abstração do trabalho ${ }^{14}$, a indústria da informação passa a buscar no mercado de trabalho profissionais capazes de gerenciar seu acervo informacional. Entretanto, mais que uma formação em biblioteconomia ou em ciência da informação, as organizações passam a valorizar a polivalência, o domínio do universo tecnológico e as atitudes comportamentais:

“Enquanto a possessão de um certificado credenciado ou um diploma de uma escola de biblioteconomia ou ciência da informação é freqüentemente a qualificação necessária e suficiente para a carreira na área de biblioteconomia e documentação, este tem um peso bem menor na indústria de informação" (Cronin, 1983, p. 13)

${ }^{14}$ É necessário nesse momento maior reflexão sobre o processo e prática do trabalho, pela via do distanciamento ou pela abstração.
Caballero V aldés \& Perón González (1998), G rover et al. (1997) e O rtega Carrasco \& Sanchez V anderkast (1998) fazem eco a Cronin (1983), ao ressaltar a importância de qualificações comportamentais para a atuação dos profissionais em questão, assim como a necessidade de uma reestruturação dos cursos de modo a adequá-los aos novos requerimentos do mercado de trabalho. Como síntese dos el ementos relacionados por estes autores, como importantes para a capacitação dos profissionais da informação, destacamos: a educação continuada, a adaptabilidade social, a capacidade de mobilizar seu conhecimento para o alcance dos objetivos da organização, o aprender a aprender, a sociabilidade, a lealdade e a responsabilidade. A novidade da discussão atual parece residir na ênfase dada à educação continuada, às qualificações tácitas e a atitudes comportamentais.

Intensificam-se as pressões para rápida adaptação do setor acadêmico à nova conformação do mundo do trabalho, aliadas a um novo fator: o profissional da informação também passa a ser cobrado a investir em seu aperfeiçoamento contínuo, seja este aperfeiçoamento pela via da educação continuada e/ou por aprendizado autônomo; por sua capacidade de articular e aprofundar conhecimentos que respondam às demandas do setor produtivo, ou por sua capacidade de transferir para 0 trabalho sua vivência profissional e sociocultural. A qualificação profissional passa a ser "um fator coadjuvante", mas não determinante do sucesso profissional, uma vez que a esta se aliam "a trajetória de vida do profissional (antes mesmo de sua formação acadêmica), suas aptidõesculturais, profissionais, políticas e sociais" (M archiori, 1992, p. 3).

Segundo H after $\&$ W ollss (1998), há um consenso entre os diversos atores da área de informação (professores, gerentes e profissionais) quanto à importância da educação continuada como forma de sobrevivência e desenvolvimento profissional. Em seu estudo acerca das pesquisas realizadas sobre a necessidade de educação continuada dos bibliotecários ${ }^{15}$, constatam que, apesar das diferenças de metodologia, escopo, faixa etária do grupo pesquisado etc. dessas pesquisas, o fantasma do descompasso tecnológico é presente entre os profissionais, tanto que "o mantra que todos os pesquisados entoam é 0 de solicitação por tecnologia, mais solicitação por tecnologia, e ainda mais solicitação por tecnologia" ( $\mathrm{H}$ after $\&$ W ollss, 1998, p. 2). M as, embora a tecnologia informacional seja um componente importante da

${ }^{15} \mathrm{O}$ estudo priorizou pesquisas não publicadas, realizadas na $C$ alifórnia (EUA), entre 1996 e 1997 (H after \& W ollss, 1998). 
realidade contemporânea e da (re)definição do processo de trabalho, as análises sobre os novos requerimentos do conteúdo do trabalho dos profissionais da informação sinalizam não para a operacionalização tecnológica, mas para uma intensificação do trabalho abstrato (ensino de ferramentas informacionais, gerenciamento, planejamento e pesquisa), onde o conhecimento de tecnologia informacional é importante, mas não determinante para a realização do mesmo. Isto leva as autoras a concluir que os profissionais estão tendo uma percepção distorcida sobre os elementos necessários para sua educação continuada e sua conseqüente manutenção no mundo do trabalho:

"É triste dizer que, se os resultados das pesquisas refletirem a realidade, os bibliotecários estão selecionando cursos de educação continuada que são mais adequados aos novos requerimentos efetuados pelo mercado de trabalho aos auxiliares de biblioteca!" (H after \& W ollss, 1998, p. 12).

O s cursos de biblioteconomia e documentação vêm implementando ações visando a reformular seus currículos, apesar de reconhecerem a impossibilidade de o ciclo de formação profissional acompanhar os saltos tecnológicos e a velocidade a que está sendo submetida a sociedade contemporânea ${ }^{16}$.

0 s resultados preliminares de uma pesquisa realizada pela Faculdade de Biblioteconomia da Pontifícia U niversidade Católica de Campinas (Fabi/Puccamp), visando a adequar a oferta de seus cursosà realidade do mercado de trabal ho, sinalizam que o perfil do profissional da informação desejado pelo empresariado da Cidade de Campinas (SP) e região está mais relacionado a qualificações tácitas do que a uma qualificação profissional formal:

"A expectativa maior é em relação ao comportamento do profissional, espera-se que tenh a a capacidade de entender a missão da organização em que está inserido, que saiba trabalhar em equipe e também que o bibliotecário seja um profissional correto, que tenha iniciativa, motivação, perspicácia, seja crítico e receptivo à (sic) mudanças que tenha seriedade" (Beraquet et al., 1997, p.10).

Contudo, a área de atuação dos profissionais da informação não se restringe às empresas, mas abrange espaços vinculados à preservação da memória, educação, disseminação cultural etc. D e acordo com Kobashi (1997), a diversidade de espaços de atuação do profissional da

${ }^{16}$ Ver Kobashi (1997) e M archiori (1992). informação impossibilita a determinação de uma estrutura (curricular) rígida. Essa constatação levou a reformulação do curso de biblioteconomia da Escola de Comunicação e A rtes da Universidade de São Paulo (ECA/USP) a privilegiar uma formação global, que contribuísse para o desenvolvimento do espírito crítico dos alunos. 0 projeto pedagógico da ECA/USP se norteou por um currículo flexível, que possibilitasse liberdade ao aluno na escolha de disciplinas optativas, resguardando um núcleo básico (currículo mínimo) que permite aos alunos contato com questões específicas da área.

"O aspecto mais importante a ser considerado na formação é a capacidade de resposta às mudanças ${ }^{17}$, isto é, preparar os alunos para um desempenho multifuncional, face à variedade de situações colocadas pelo mundo do trabalho, muitas delas imprevisíveis" (Kobashi, 1997, p. 40).

A opção da ECA/USP por um currículo que privilegie a diversidade e a pesquisa desenvolvida pela Fabi/Puccamp são ações que sinalizam uma sintonia dos cursos de formação profissional com as mudanças em curso, embora não se identifique um posicionamento uniforme quanto às tendências para formação acadêmica dos profissionais da informação no futuro.

A nte a diversidade de espaços de atuação profissional e a dificuldade de se estabelecer um consenso quanto ao perfil profissional do bibliotecário, Mueller (1989) propõe que sua formação profissional ocorra a partir da associação entre profissões afins.

"Tal associação poderia se dar no sistema de formação profissional, com o estabelecimento de uma estrutura que permitisse movimentação não só no sentido vertical, como hoje existe, de bacharelado para mestrado e doutorado em uma mesma carreira, mas entre carreiras. Isto é, pessoas com formação básica diversa poderiam cursar os demais níveis da estrutura de formação profissional de quaisquer dasáreas afins, com reconhecimento legal. H averia então não apenas a classe bibliotecária, mas uma classe de profissionais da informação, da qual os bibliotecários fariam parte"(M ueller, 1989, p. 69).

Já Pinheiro (1997, p. 36) vê, na educação continuada e nos programas interdisciplinares, uma alternativa para superação "dos impasses hoje vividos de formação e prática". Para T arapanoff (1997), o mais provável é que a formação dos profissionais da informação ocorra na pósgraduação, e não mais nos cursos de graduação, seguindo uma tendência internacional.

${ }^{17} \mathrm{G}$ rifo da autora. 


\section{Educação, trabalho e o delineamento de novos perfis profissionais: o bibliotecário em questão}

Pelo exposto anteriormente, não se identifica um argumento consensual entre as propostas de reformulação dos cursos de biblioteconomia. Todavia, fica claro que os cursos de formação profissional reconhecem as transformações por que vem passando a sociedade contemporânea e estão buscando equacionar essas questões de forma a capacitar os indivíduos com saberes que Ihe possibilitem articular sua permanência no mercado de trabalho, poisque um ensino baseado na última novidade tecnológica dificilmente encontrará respaldo no mercado de trabalho do futuro.

\section{CONCLUSÃO}

Tanto a iniciativa da FID em desenvolver uma pesquisa em nível mundial, quanto a preocupação dos cursos de formação profissional em reformular seus currículos sinalizam mudanças no perfil dos profissionais da área de informação, em contextos geográficos e socioeconômicos completamente diversos.

A literatura consultada nos mostra um redimensionamento da qualificação profissional, acompanhada da necessidade de o indivíduo adaptar seu acervo cognitivo e articular sua personalidade para interagir com o mundo do trabalho. 0 termo "moderno", utilizado pela FID para adjetivar o profissional da informação, parece acentuar um ritual de passagem para um novo padrão profissional que exigiria dos profissionais redobrados esforços em educação continuada, integração organizacional e capacidade de atuar em equipe.

T odavia, o perfil delineado pela literatura e pelas pesquisas se aproxima daquele requerido pela especialização flexível. A s análises são quase que sincrônicas em suas conclusões e recomendações, refletindo, em maior ou menor grau, a demanda do setor produtivo por um trabalhador com aptidões que Ihe possibilitem direcionar e redimensionar seu acervo cognitivo em função das metas e objetivos da organização, em paralelo ao investimento individual em treinamento e capacitação. M as, longe de apontar soluções ou mesmo recomendações concretas que atendam à necessidade de educação continuada dos profissionais da informação, as pesquisas são um reflexo do movimento de fragmentação e dispersão que se instala no mundo do trabalho, espel hando a insegurança dos profissionais ante a velocidade das inovações organizacionais e tecnológicas, assim como sua dificuldade em sistematizar conhecimentos científicos-tecnológicos para sua educação continuada em um cenário em que o próprio mundo do trabalho parece enfatizar o plano subjetivo do indivíduo, em termos de suas competências pessoais.
Dentro dessa dinâmica é importante que as ações direcionadas à formação profissional e à educação continuada destes profissionais estejam sedimentadas na compreensão dos processos transformação por que passa o mundo do trabalho, o que permite aos indivíduos a percepção das materialidades que se articulam na confecção e validação de um novo modelo de qualificação profissional e que contribuem para o estrangulamento do mercado de trabalho. Isso, posto que o delineamento de um novo perfil profissional não é exclusivo da área da informação, mas endógeno ao novo modelo econômico, que introduz novas formas de gestão do trabalho e de socialização dos indivíduos, valorizando a atuação em equipe, a interdisciplinaridade, 0 aprendizado contínuo e atitudes comportamentais.

A rtigo aceito para publicação em 01-08-2000

\section{REFERÊNCIAS BIBLIOGRÁFICAS}

A LMA DA DE A SCENCIO, M argarita. Las políticas de información en un mundo globalizado. In: INFO'97. A nais... Havana, 1997. Disponível em disquete.

A RRUDA, M aria da Conceição Calmon. Libraries, new technologies and human resources: the challenge to the $21^{\text {st }}$ century. In: IFLA GENERAL CONFERENCE, 63., 1997, Copenhagen. Booklet 0. Copenhagen : IFLA , 1997. p. 39-47. Disponível em http://www.ifla.org/ IV /ifla63/63arrm.htm.

ARRUDA, Maria da Conceição Calmon. 0 profissional da informação face à revolução científico-tecnológica: novas ou vel has qualificações? 1999. 133 p. Dissertação (M estrado) - CNPq-IBICT/UFRJ-ECO, Rio de Janeiro, 1999.

ARRUDA, Maria da Conceição Calmon. Reflexos do processo de globalização na capacitação profissional. Informação \& Sociedade: estudos, João Pessoa, v. 8, n. 1, p.11-24, 1998.

ARRUDA, Maria da Conceição Calmon. Revolução informacional, globalização e as mudanças na capacitação profissional. Informare, Rio de Janeiro, v. 3, n. 1/2, p. 165-173, jan./dez., 1997.

A SSIS, M arisa de. A Educação e a formação profissional na encruzilhada das velhas e novas tecnologias. In: FERRETTI, Celso João et al. N ovas tecnologias, trabalho e educação : um debate multidisciplinar. Petrópolis : V ozes, 1996. p. 189-203.

BERA Q UET, V era Silvia M arão et al. A s expectativas das intituições empregadoras do bibliotecário como subsídios ao aprimoramento de sua formação profissional. In: CONGRESSO BRASILEIRO DE BIBLIOTECONOMIA E DOCUMENTAÇÃ O, 18, 1997, São Luís, M A. A nais... São Luís: FEBA B/A PBEM , 1997. Disponível em disquete.

BO URDIEU, Pierre. A dupla verdade do trabalho. In: DESA ULNIERS, Julieta Beatriz Ramos ( 0 rg.). Formação \& trabalho \& competência : questões atuais. Porto A legre : EDIPUCRS, 1998. p. 221- 226.

CABA LLERO VALDÉS, O dalys; PERÓN GONZÁ LEZ, Sandra. El bibliotecológo y el profesional de la información modernos: ética, papeles y perfiles. Ciencias de la información, v. 29, n. 1, p. 3-13, mar. 1998.

CARVA LHO , Ruy de Q uadros. Capacitação tecnológica, revalorização do trabalho e educação. In: FER RET TI, Celso João et al. N ovas tecnologias, trabalho e educação: um debate multidisciplinar. Petrópolis: Vozes, 1996. p. 93-127. 


\section{Maria da C onceição C almon A rruda / R egina M aria Marteleto / D onaldo B ello de Souza}

CA STEL, Robert. As metamorfoses do trabalho. In: FIORI, J. L.; LO UREN ÇO, M. S. de; NORONHA, J. C. de (O rg.). G lobalização: 0 fato e o mito. Rio de Janeiro : UERJ, 1998. p. 147-163.

CA STELLS, M anuel. The rise of the network society. M alden : Blackwell, 1996. v. 1.

CORIAT, Benjamin. El taller y el robot: ensayos sobre el fordismo y la producción en masa en la era de la electrónica. M adri : Siglo V eintiuno de España, 1992. 266 p.

CRONIN, Blaise. Post-industrial society: some manpower issues for the library/information profession. Journal of Information Science, v. 7, p. $1-14,1983$.

CRO W LEY, Bill; BRA CE, Bill. A choice of future: is it libraries versus information? A merican Libraries, v. 30, n. 4, p. 76-79, A pr. 1999.

DELUIZ, N eise. Formação do trabalhador em contexto de mudança tecnológica. Boletim Técnico do SE N A C, Rio de Janeiro, v. 20, n. 1, p. 14-25, jan./abr. 1994.

FID. Results of FID's survey of the modern information professional. Disponível em: http://fid.conicyt.cl:8000/mip.htm. A cesso em: 15 jun. 1999.

FIGUEIRED 0, Nice M enezes de; LIMA, Regina Célia M ontenegro de. Desenvolvimento profissional e inovações tecnológicas: professional development and technological innovations. Revista da Escola de Biblioteconomia da U FM G, Belo Horizonte, v. 15, n. 1, p. 47-67, mar. 1986.

FREEM A N, Chris. Information highways and social change. O ttawa : IDRC, 1995. 22p.

FRIGOTTO, Gaudêncio. Educação e a crise do capitalismo real. São Paulo: Cortez, 1996. $231 \mathrm{p}$.

GROVER, Robert et al. The wind beneath our wings: chaos theory and the butterfly effect in curriculum design. Journal of Education for Library and Information Science, v. 38, n. 4, p. 268-282, Fall 1997.

HABERMAS, J. A nova intransparência: a crise do estado de bemestar social e 0 esgotamento das energias utópicas. N ovos Estudos C EBRA P, São Paulo, n. 18, p. 77-102, 1987.

HAFTER, Ruth; W OLLSS, Blanche. CE curricula: surveys produce more questions than answers. In: IFLA GENERAL CONFEREN CE, 64, 1998, A msterdan. Proceedings... A msterdan : IFLA , 1998. Disponível em: http://www.ifla.org/lV/ifla64/05/-136e.htm. A cesso em: 02 jun. 1999.

HARVEY, David. Condição pós-moderna. 6. ed. São Paulo : Loyola, 1996. $349 \mathrm{p}$.

HIRATA, H elena. Da polarização das qualificações ao modelo da competência. In: FERRETTI, Celso João et al. N ovas tecnologias, trabalho e educação: um debate multidisciplinar. Petrópolis: V ozes, 1996. p. 128142.

JONES, Bryn, WOOD, Stephen. Q ualifications tacites, division du travail et novelles technologies. Sociologie du T ravail, n. 4, p. 407-421, 1984.

KOBASHI, Nair Yumiko. Formação do profissional da informação: 0 projeto pedagógico da ECA -U SP. In: SEM IN Á RIO S DE EST U DOS DE INFORM A ÇÃ O , 1, 1996, N iterói. A nais... N iterói : EDUFF, 1997. p. 25-31.

KUEN ZER, A cacia Zeneida. Ensino de 20 grau: o trabal ho como princípio educativo. São Paulo : Cortez, 1988. 166 p.

KUENZER, A cacia Zeneida. A s novas bases materiais de produção: 0 princípio educativo do trabalho industrial moderno. In: SEM IN Á RIO GLOBA LIZA ÇÃ O E ESTA DO ; UNIVERSIDADE EM MUDA N ÇAS, 1995, Curitiba. A nais... Curitiba, 1995. 15 p.
LOJKINE, Jean. A Revolução Informacional. São Paulo : Cortez, 1995. 316 p.

LOPE, A ndreu; MA RTIN A RTILES, A . Las relaciones entre formacion y empleo: ¿que formacion, para que empleo? In: DESA U LN IERS, Julieta Beatriz Ramos ( 0 rg.). Formação \& trabalho \& competência: questões atuais. Porto A legre: EDIPUCRS, 1998. p. 179-219.

MACHADO, Lucília Regina de Souza. Educação e os desafio das novas tecnologias. In: FERRETTI, Celso João et al. N ovas tecnologias, trabalho e educação: um debate multidisciplinar. Petrópolis : V ozes, 1996. p. $169-188$.

M A C H A D O , Lucília Regina de Souza. H umanismo e tecnologia numa perspectiva de qualificação profissional. Tecnologia E ducacional, v. 21, n. 107, p. 60-63, jul./ago. 1992.

MA CHA DO, Lucília Regina de Souza. T ransformações tecnológicas e padrão de qualificação. Educação em revista: Revista da Faculdade de Educação da UFM G, Belo Horizonte, n. 14, p. 48-54, dez.1991.

MARCHIORI, Patrícia. A posição relativa dos profissionais de biblioteconomia, jornalismo e informática no campo de atividade de informação no município de C uritiba: anál ise da formação acadêmica na U niversidade Federal do Paraná, em conjunto com indicadores sociológicos. 1992. 383 p. Dissertação (M estrado) - U FRJ/ECO/IBICT, Rio de Janeiro, 1992.

MEN OU, M ichel. Especial : entrevista com M ichel M enou. Informativo IBIC T, v. 16, n. 3, p. 7-8, maio/jun. 1996.

M ÜELLER, Suzana Pinheiro M achado. Perfil do bibliotecário, serviços e responsabilidades na área de informação e formação profissional. Revista de Biblioteconomia de B rasília, Brasília, v. 17, n. 1, p. 63-70, jan./jul. 1989.

OFFE, Claus. C apitalismo desorganizado. São Paulo : Brasiliense, 1989a.

OFFE, Claus. Trabalho: uma categoria - chave da sociologia? Revista Brasileira de Ciências Sociais, São Paulo, v. 4, n. 10, p. 5-19, jan. 1989b.

ORTEGA CARRASCO, Laura; SANCHEZ VANDERKAST, Egbert. The information professional in a networked society. A slib Proceedings, v. 50, n. 5, p. 95-99, M ay 1998.

PA IVA, V anilda. Produção e qualificação para o trabalho: uma revisão da bibliografia internacional. Rio de Janeiro : UFRJ/IEI, 1989. 72 p. (Texto para discussão, 214).

PINHEIRO, Lena Vânia. O pensar e o fazer do profissional de informação. In: SEM IN Á RIO S DE EST UDOS DE IN FORM A ÇÃ O , 1, 1996, N iterói. A nais... Niterói : EDUFF, 1997. p. 33-38.

ROBRED 0, Jaime. Informação e transformação: reflexões sobre 0 futuro da biblioteca. Revista de Biblioteconomia de Brasília, Brasília, v. 14, n. 1, p. 51-69, jan./jun. 1986.

SA LERM O , M ário Sérgio. T rabalho e organização na empresa industrial integrada e flexível. In: FERRETTI, C elso J oão et al. N ovas tecnologias, trabalho e educação: um debate multidisciplinar. Petrópolis : V ozes, 1996. p. 54-76.

SCH ILLER, H erbert I. Information inequality: the deepening social crisis in A merica. N ew York : Routledge, 1996. 149 p.

ST RO O BA NTS, M arcelle. A visibilidade das competências. In: RO PÉ, Françoise, T A N GUY, Lucie. Saberes e competências: 0 uso de tais noções na escola e na empresa. Campinas : Papirus, 1997. p. 135-166.

TA N GUY, Lucie. Competências e integração social na empresa. In: RO PÉ, Françoise; TA N GUY, Lucie. Saberes e competências: 0 uso de tais noções na escola e na empresa. Campinas : Papirus, 1997. p. 167-197.

TARAPANOFF, Kira. Perfil do profissional da informação no Brasil: diagnóstico de necessidade de treinamento e educação continuada. Brasília: IEL/DF, 1997. 134p.

TOFFLER, A Ivim. A terceira onda: a morte do industrialismo e o nascimento de uma nova civilização. 2. ed. Rio de Janeiro : Record, 1980. 491 p. 